\title{
PRospective EnvironMental Impact asSEment (premise): a streamlined approach to producing databases for prospective Life Cycle Assessment using Integrated Assessment Models
}

\author{
Sacchi, R. ${ }^{1, *}$, Terlouw, T. ${ }^{1,2}$, Siala, K. ${ }^{3}$, Dirnaichner, A. ${ }^{3}$, Bauer, C. ${ }^{1}$, Cox, B. ${ }^{4}$, Mutel, C. ${ }^{1}$, \\ Daioglou, V. ${ }^{5,6}$, Luderer, G. ${ }^{3,7}$ \\ 1 = Technology Assessment group, Laboratory for Energy Systems Analysis, Paul Scherrer Institut, Villigen, Switzerland \\ 2 = Institute of Energy and Process Engineering, ETH Zurich, Zurich, Switzerland \\ 3 = Potsdam Institute for Climate Impact Research, Potsdam, Germany \\ $4=$ INFRAS, Bern, Switzerland \\ 5 = Copernicus Institute of Sustainable Development, Universiteit Utrecht, The Netherlands \\ $6=$ PBL Netherlands Environmental Assessment Agency, The Hague, The Netherlands \\ 7 = Technische Universität Berlin, Berlin, Germany \\ *Corresponding author details: email - romain.sacchi@psi.ch, telephone - +417676219 22, fax - +41563102199
}

\begin{abstract}
Prospective Life Cycle Assessment (pLCA) is useful to evaluate the environmental performance of current and emerging technologies in the future. Yet, as energy systems and industries are rapidly shifting towards cleaner means of production, pLCA requires an inventory database that encapsulates the expected changes in technologies and the environment at a given point in time, following specific socio-techno-economic pathways. To this end, this study introduces premise, a tool to streamline the generation of prospective inventory databases for pLCA by integrating scenarios generated by Integrated Assessment Models (IAM). More precisely, premise applies a number of transformations on energy-intensive activities found in the inventory database ecoinvent according to projections provided by the IAM. Unsurprisingly, the study shows that, within a given socio-economic narrative, the climate change mitigation target chosen affects the performance of nearly all activities in the database. This is illustrated by focusing on the effects observed on a few activities, such as systems for direct air capture of $\mathrm{CO}_{2}$, lithium-ion batteries, electricity and clinker production as well as freight transport by road, in relation to the applied sector-based transformation and the chosen climate change mitigation target. This work also discusses the limitations and challenges faced when coupling IAM and LCA databases and what improvements are to be brought in to further facilitate the development of pLCA.
\end{abstract}

\section{Highlights}

- $\quad$ Prospective LCA can benefit from projections of models such as IAM

- $\quad$ premise streamlines the production of LCA databases based on prospective scenarios

- Emissions and energy efficiencies of major industries are aligned with IAM scenarios 
- Stricter greenhouse gas targets result in larger transformations in the LCA database

- However, such targets result in increased LCA impacts other than global warming

\section{Keywords}

prospective scenario, integrated assessment model, emerging technology, life cycle assessment

Word count excluding Abstract, Keywords, Abbreviations, Acknowledgement, Funding sources, Data Availability and References: approx. 6,500

Single figure(s): 1

Multi-part figure(s): 6

Table(s): 0

$\begin{array}{llll}\text { Abbreviations } & & \\ \text { BECSS } & \begin{array}{l}\text { BioEnergy with Carbon Capture and } \\ \text { Storage }\end{array} & \text { IMAGE } & \begin{array}{l}\text { Integrated Model to Assess the Global } \\ \text { Environment }\end{array} \\ \text { BEV } & \text { Battery Electric Vehicle } & \text { IPCC } & \begin{array}{l}\text { Intergovernmental Panel on Climate } \\ \text { Change }\end{array} \\ \text { CCS } & \text { Carbon Capture and Storage } & \text { LCA } & \text { Life Cycle Assessment } \\ \text { CHP } & \text { Combined heat-power plant } & \text { LCI } & \begin{array}{l}\text { Life Cycle Inventory } \\ \text { CoP }\end{array} \\ \text { Coefficient of Performance } & \text { Li-NMC } & \begin{array}{l}\text { Lithium Nickel Manganese Cobalt } \\ \text { oxide }\end{array} \\ \text { DACCS } & \text { Direct Air Carbon Capture and Storage } & \text { pLCA } & \text { prospective Life Cycle Assessment } \\ \text { FCEV } & \text { Fuel Cell Electric Vehicle } & \text { pLCI } & \text { prospective Life Cycle Inventory } \\ \text { GHG } & \text { Greenhouse Gas(es) } & \text { REMIND } & \begin{array}{l}\text { REgional Model of Investment and } \\ \text { Development }\end{array} \\ \text { IAM } & \text { Integrated Assessment Model } & \text { RCP } & \text { Representative Concentration Pathway } \\ \text { ICE } & \text { Internal Combustion Engine } & \text { SSP } & \text { Shared Socio-economic Pathway }\end{array}$




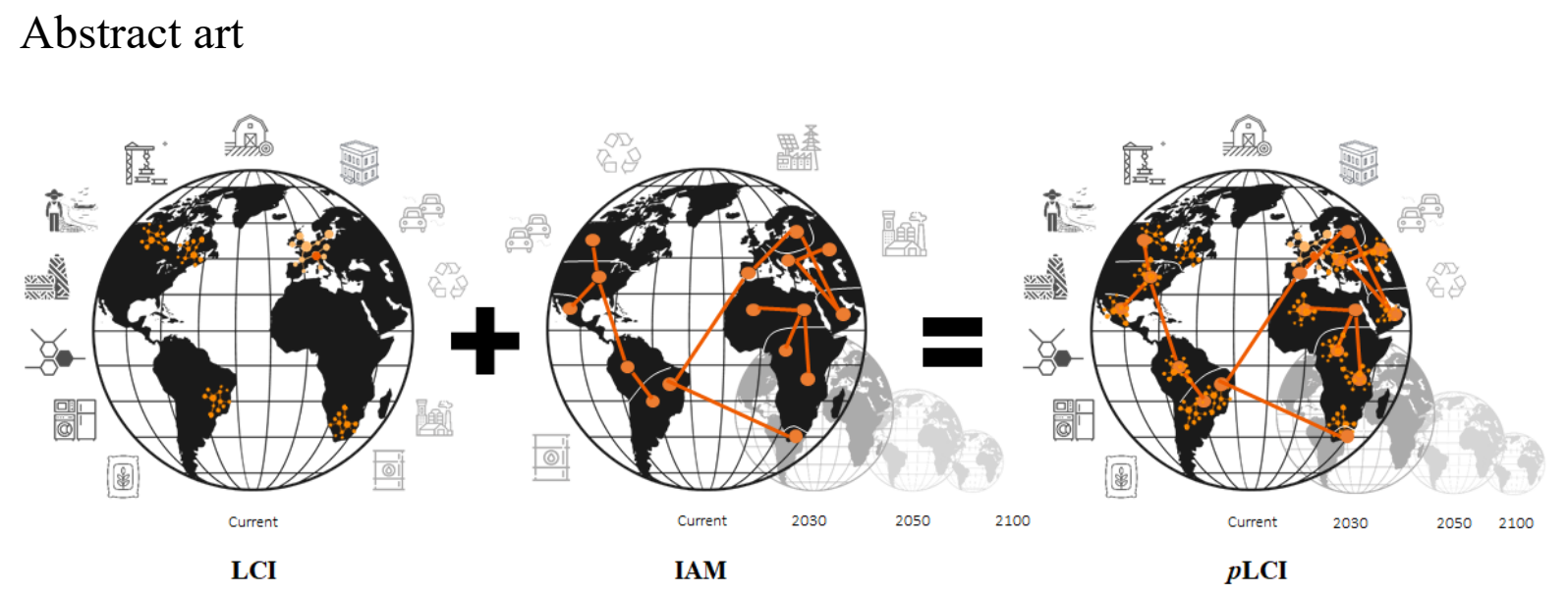

\section{Introduction}

The globalization and digitalization of the economy, as well as the electrification of industry and different means of transport, imply that the environmental footprint of products and services consumed is increasingly dependent on the performance of global supply chains and the energy systems that support them. As energy systems and industrial processes are rapidly changing in the attempt to reduce GHG emissions, understanding the expected changes in energy supply becomes as important as correctly modeling the product itself for performing LCA and quantifying environmental burdens in a comprehensive way. Furthermore, decision support in environmental and climate policy, for example, usually requires insights into the performance of future technologies. Traditional LCA and its underlying static database is poorly equipped to this end. This gave way to pLCA, where projections in time are introduced in LCI [1].

The body of pLCA literature is broad [2-7]. However, advanced pLCA, in which LCA is informed by prospective energy systems or integrated assessment models, is relatively rare and has only recently gained attention [1]. First exercises linking prospective energy system models and LCA were limited to power generation, residential heating and passenger vehicles. They were used to either quantify the environmental burdens of single future technologies, or environmental impacts on a system level for different transformation pathways until the mid-century. Gibon et al. [8] used the ecoinvent database v.2.2 [9] together with energy scenarios from the International Energy Agency and prospective industry-related inventories from the NEEDS database to generate the "THEMIS" modeling framework - an integrated, prospective hybrid LCA model that covers nine world regions with a time frame of up to 2050. Future performance of power generation technologies and selected industrial activities were integrated in the background LCI database. The THEMIS 
Re-submitted to Renewable and Sustainable Energy Reviews on February ${ }^{\text {st }}, 2022$.

framework was further developed by Arvesen et al. [10] who presented life cycle coefficients for a wide range of future power generation technologies up to 2050. Pehl et al. [11] built on THEMIS to quantify life cyclebased energy use as well as direct and indirect GHG emissions coefficients for power generation technologies and the global electricity sector up to 2050 according to different scenarios of the IAM REMIND [12]. Finally, Luderer et al. [13] built on THEMIS to combine IAM scenarios with pLCA to explore how alternative technology choices in the power sector compare in terms of non-climate environmental impacts at the system level. Another approach more directly integrating IAM into LCA has been proposed in [14-16]. All three studies used projections from the IAM IMAGE [17] to generate prospective pLCI databases and used these to conduct the pLCA of passenger vehicles. The same approach, but with the IAM E3ME-FTT-GENIE [18], was used by Knobloch et al. [19]. They addressed the climate change impact potential of future passenger vehicles and residential heating systems. Using a similar approach, Rauner et al. [20] quantified the life-cycle-based cobenefits of a global coal-exit on human health and ecosystems, this time based on prospective scenarios from REMIND; and Harpprecht et al. [21] performed a prospective LCA of key metals' supply integrating scenarios from IMAGE. More recently, Dirnaichner et al. [22] coupled the transport model EDGE-T [23] with REMIND to calculate mid- and endpoint LCA indicators for the European passenger car fleet under different policies. The key element of these studies was a modification of the background LCI database that resulted in pLCI databases reflecting expected developments within the power generation sector.

These previous efforts were valuable as they introduced the idea of enhancing pLCA thanks to prospective scenarios of IAM and demonstrated its feasibility. However, these works were conducted with the assessment of specific systems in mind, without adjusting entire clusters of industrial activities other than power generation present in the pLCI database. Projecting efficiency gains and market developments within the electricity supply sector certainly encapsulates a large share of the benefits to be expected when the focus is on battery electric cars and heat pumps. But other important sources of environmental damage, such as the production of metals that enter the composition of the chassis, or the cement used to build the road infrastructures, have so far not been addressed. Additionally, the technical integration of IAM scenarios in LCI databases in these studies was not designed with a large-scale applicability that would allow the use of different IAM or LCI databases.

Building on the work of Beltran and Cox [14,15], this paper presents a tool that follows a streamlined approach to integrating IAM prospective scenarios into the LCI database ecoinvent [24] to allow for pLCA. More specifically, the tool allows: 
Re-submitted to Renewable and Sustainable Energy Reviews on February ${ }^{\text {st }}, 2022$.

- the integration of expected transformations within five major energy-intensive sectors, namely power generation, cement and steel production, freight and passenger road transportation, and supply of conventional and alternative fuels

- applicability across different IAM

- the export of pLCI databases to different LCA software

With these functionalities, pLCI databases can be generated in a consistent manner across prospective scenarios based on socio-economic pathways and climate change mitigation targets, produced by one or multiple IAM. It also allows for the comparison of pLCI databases based on scenarios that follow a similar combination of socioeconomic pathway and climate change mitigation target, but whose targets are reached based on different technology choices or constraints. Hence, premise contributes to the improvement of the quality of pLCA, as lack of transparency (i.e., modelling choices) and consistency (i.e., between the LCA model and the scenario) are aspects that currently undermine this emerging field, according to [4]. Finally, the tool allows for consistent and reproducible databases giving similar results regardless of the LCA software used. This last aspect echoes the work of Joyce et al [25] which demonstrates the interesting concept of recipes, used to reproduce (modified) prospective LCI databases. With such aspects being handled by premise, practitioners can focus on the foreground modeling of the product system studied.

The next section describes the approach used to produce pLCI databases. Its benefits for prospective LCA are illustrated in Section 3 with the example of road construction, battery production, capture of $\mathrm{CO}_{2}$ from the atmosphere and a few other cases. These examples rely on technologies that will play an important role in deep de-carbonization pathways (i.e., cement production, metals extraction and recycling, power generation). They are however energy- and material-intensive, and are expected to undergo rapid development in the next decades.

\section{Method}

The open-source Python library premise builds on the work of Beltran and Cox [14-16] and increases the extent of prospective scenario integration in LCA across multiple models (REMIND and IMAGE are used as case studies in this paper, but the method can be extended to others), different versions of the ecoinvent database (from 3.5 to 3.8 ) and multiple industry sectors such as power generation, cement, steel and fuel production. premise is currently able to work "out-of-the-box" with IMAGE and REMIND, although extending its ability to work with other IAM is straightforward. Mapping files available as part of the tool's documentation [26] associate the IAM, premise and ecoinvent terminologies and minimize the effort when extending the tool's 
compatibility to other IAM models. It is worth noting however that the extent to which the integration of a given sector is performed often depends on the information the IAM model can provide. premise limits the use of data from external sources to maximize the consistency between the resulting pLCI database and the IAM scenario it is built from.

Figure 1 depicts the general workflow to produce a pLCI database. In Step 1, IAM prospective scenarios are used as inputs together with the LCI database (in this case, ecoinvent). Section 2.1 describes the nature and content of IAM scenarios. In Step 2, using the library wurst [27], premise operates a number of transformations on the LCI database. This step requires the use of additional inventories to represent emerging and future technologies not originally available in the LCI database. This is done by collecting inventories from the literature (e.g., hydrogen and synthetic fuel production, direct air capture, heavy-duty trucks, etc.). The second step results in a modified LCI database for a given year, transformed according to the prospective scenario chosen. Section 2.2 describes the approach used to operate such transformations. Step 3 consists of exporting the database into a format that common LCA software (i.e., Brightway2, Simapro) accept or as a set of sparse matrix representations that numerical libraries can handle. A third option consists of producing a "scenario difference file" to support a "superstructure" database that can be read by Activity Browser [28] - this option allows to write only one database to disk while being able to explore multiple scenarios - as described in [29]. Finally, Steps 4 and 5 consist of producing LCA resource and environmental indicators that feed back to the IAM. These two last steps are discussed briefly in Section 4.2 .

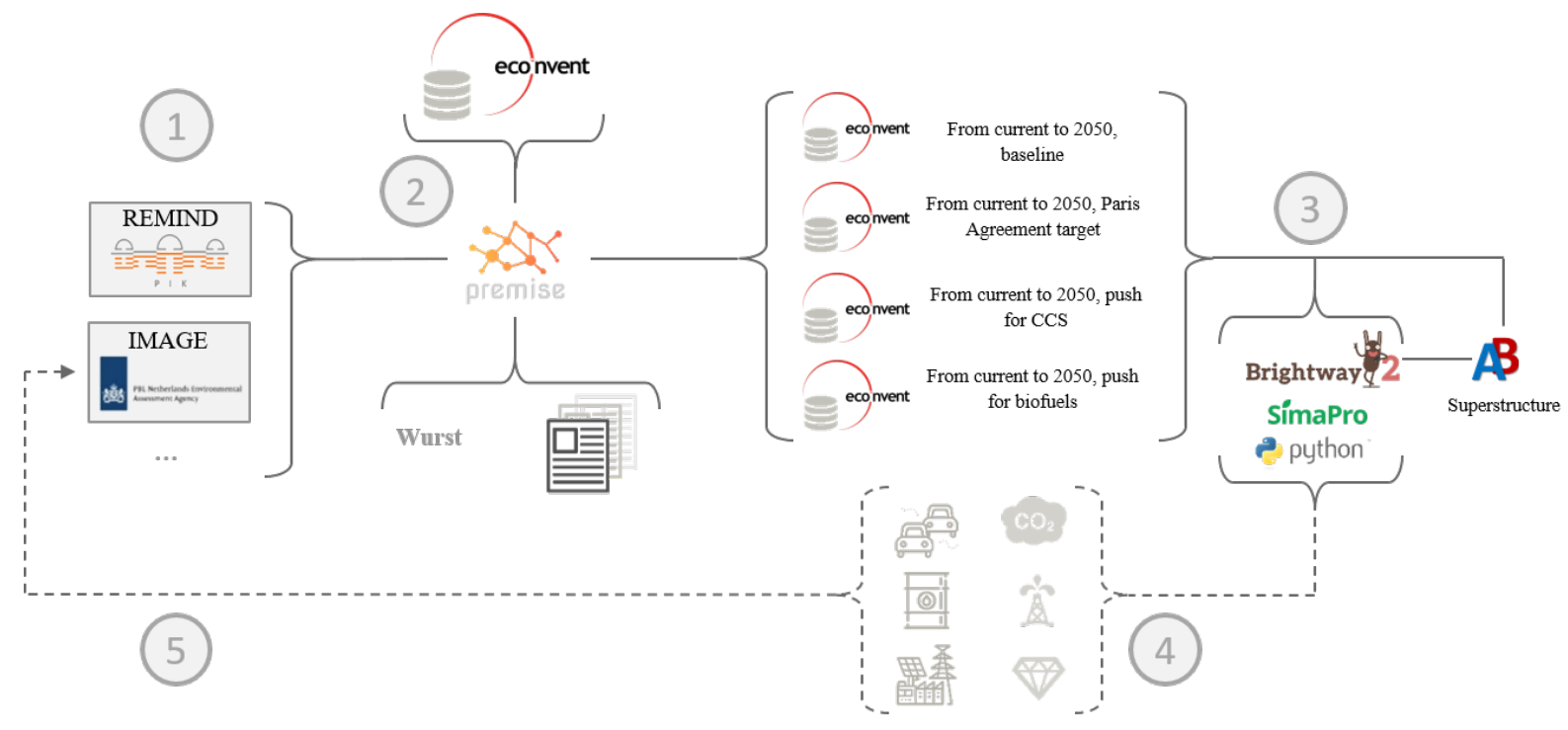

Figure 1 General IAM-LCA coupling workflow 


\subsection{IAM prospective scenarios}

Process-detailed IAM describe transformation pathways of the interlinked energy-economy-land-climate systems. They are distinct from cost-benefit IAM in that they represent the energy system and other sources of GHG emissions as well as mitigation technologies with detailed energy stocks, flows, and conversion technologies. The reader can refer to [30] for a definition of process-based IAM. Cost-benefit IAM such as DICE [31] and Fund [32], by contrast, only have a stylized representation of GHG abatement potential as a function of carbon prices, without representing underlying system changes and their interactions.

In the present study, we use REMIND v2.1 [33] and IMAGE v3.2 [17] as illustrative examples of process-based IAM. Both IMAGE and REMIND model the energy system. On the supply side, they represent a large variety of energy conversion technologies supplying electricity, liquid fuels, hydrogen and other energy carriers. On the demand side, they represent energy services and demands from the transport (refer to [23] for REMIND or [34] for IMAGE), buildings (refer to [35] for REMIND or [36] for IMAGE) and industry sectors (refer to [37] for IMAGE). Cross-linkages to land use via bioenergy and other land-based mitigation options such as afforestation or abatement of $\mathrm{CH}_{4}$ and $\mathrm{N}_{2} \mathrm{O}$ emissions from land use are part of the IMAGE model [38,39], while REMIND can be coupled to the MAgPIE land use model [40], as demonstrated in [41]. To derive climate change mitigation pathways, constraints on GHG emissions are imposed (e.g., in terms of cumulative emissions until the end of the century), and the $\mathrm{CO}_{2}$ price is adjusted iteratively to meet the target GHG emissions level. In response to the price signal, the models derive de-carbonization strategies, for instance via efficiency improvements, bioenergy [38-41], or renewables-based electrification [42]. Other environmental constraints can be considered, such as the area of land available for bioenergy and crop production. REMIND and IMAGE also represent air pollutant emissions [20] and water demands $[43,44]$ by type of power source. A crucial difference between IMAGE and REMIND are assumptions on how the decision-making process is formed. The intertemporal optimization used in REMIND generally implies perfect foresight by agents taking investment decisions. IMAGE, by contrast, uses recursive-dynamic modeling (i.e., system configurations in each time step are determined sequentially based on the state of the system in the previous time step). In both models, the output includes time series in five or ten-year steps of primary, secondary, final, and useful energy, for each geographical region and by fuel type, technology, or application. The number of regions differs across IAM (e.g., 12-21 for REMIND depending on configuration, 26 for IMAGE). 
Re-submitted to Renewable and Sustainable Energy Reviews on February ${ }^{1 \text { st }}, 2022$.

The IAM community has developed SSP as a means of structuring uncertainty about future socio-economic developments, such as national GDP, education and demographics [45]. In parallel, RCP describe several potential trajectories for atmospheric radiative forcing by 2100 , ranging from 1.9 to $8.5 \mathrm{~W} / \mathrm{m}^{2}$. Combining both frameworks, IAM make long-term energy and land-use projections that comply with atmospheric radiative forcing targets (given by the RCP) across a set of societal and economic conditions (given by the SSP). The reader may refer to [46] for further details on how RCP and SSP relate. Bisinella et al [4] qualify these prospective scenarios as normative, as they describe potential pathways from the present to reach a climatebased target in the future.

Both REMIND and IMAGE are among the five IAM that were used for deriving marker scenarios of the Shared Socio-Economic Pathways [47], and they also contributed with a substantial share of the scenarios assessed in past IPCC reports $[48,49]$. This study displays the integration of IAM scenarios in the LCI database ecoinvent using the SSP2 "Middle-of-the-Road" socio-economic pathway. This pathway describes developments in line with what has been historically observed in the past century. The reader can refer to [50] for additional detail on the SSP2 pathway. Based on this, prospective scenarios that comply with the climate change mitigation targets RCP 6, 2.6 and 1.9 are presented - corresponding to a global atmospheric temperature increase by 2100 with respect to pre-industrial levels of 3.5 degrees C., below 2 degrees C. and 1.5 degrees C., respectively. premise also works with prospective scenarios that consider other socio-economic pathways and climate change mitigation targets.

\subsection{Transformations on the LCI database}

A LCI database usually presents itself as a pair of matrices populated with product and emission exchanges between man-made systems (hereafter referred to as the "technosphere") and parts of the natural world (hereafter referred as the "biosphere"). A simplified representation of an LCI database is shown in Figure 2.awhere both technosphere and biosphere flows are represented in the same matrix. In this example, Product A (first column) is supplied via the global market for Product A (first row). This market receives inputs from Czech Republic, Norway and German-based production activities (first column, second to fourth row). These production activities (second to fourth column) respectively require some fuel from the global fuel market and emit some $\mathrm{CO}_{2}$ as well as $\mathrm{NO}_{x}$ (last two rows). The global fuel market requires some input from a fuel production activity, which itself leads to some emissions. It is of course possible that the fuel production activity itself requires some inputs from the global market for Product A (seventh column, first row). premise performs a 
number of transformations on these matrices to reflect the data granularity and expected changes dictated by the IAM scenario, as shown in Figure 2.b. Markets based on IAM regions are created for certain products (green shaded cells), which receive inputs from production activities located in their respective geographical scope. Production activities based on IAM regions are also created (blue shaded cells), for which a region-specific energy efficiency is applied (yellow shaded cells) - which also affects $\mathrm{CO}_{2}$ emissions, if applicable -, as well as a region-specific correction factor for non- $\mathrm{CO}_{2}$ emissions (grey shaded cells). Additionally, activities representing emerging technologies are added to align with the IAM scenario (orange shaded cells). Finally, inputs-consuming activities relink to the newly created market activities located in their geographical area.

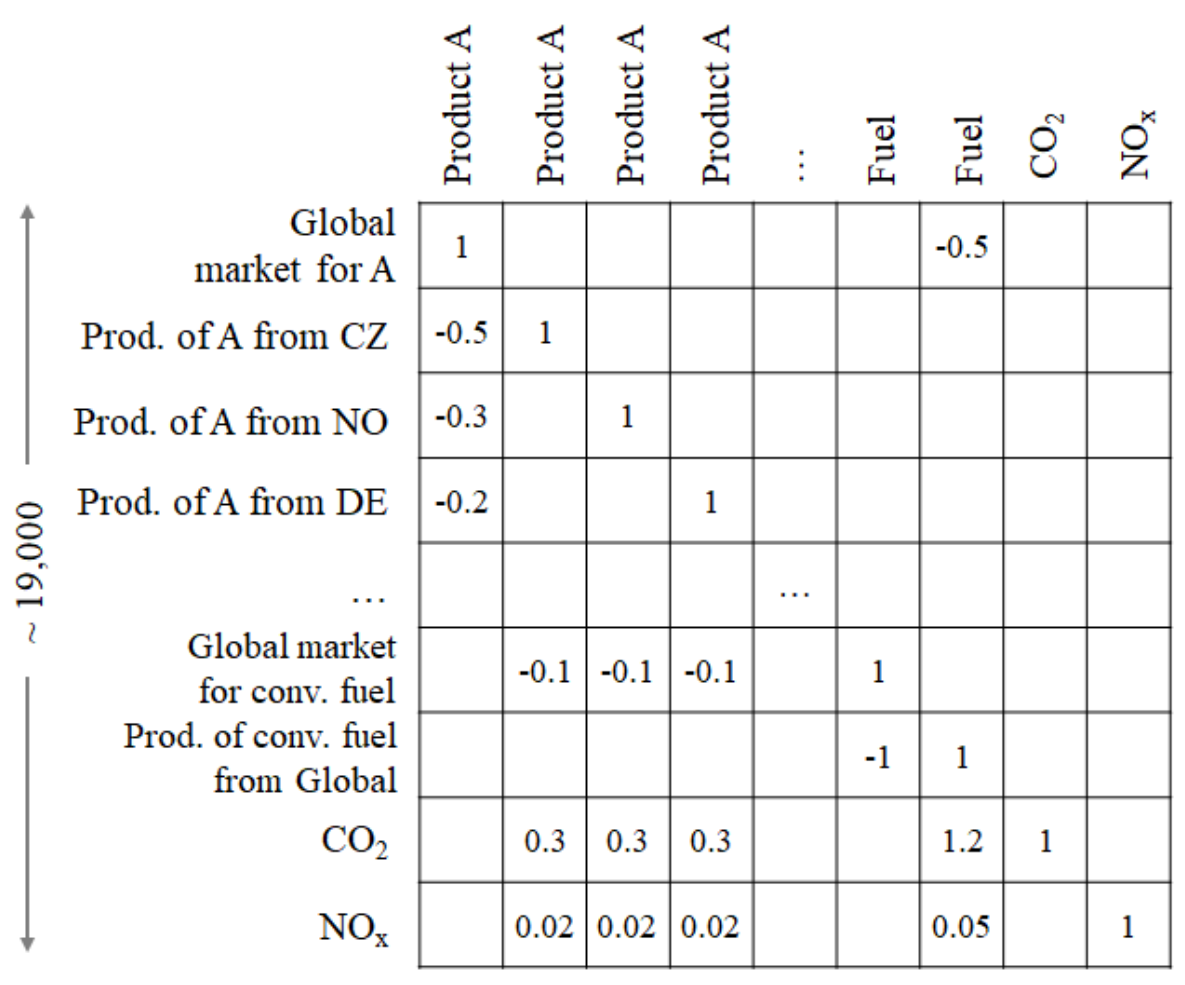

a) Simplified representation of a LCI database (positive values represent outputs, negative values represent inputs). 
Global market for A

European market for A Indian market for A

Production of A from $\mathrm{CZ}$ Production of A from NO Production of A from DE Production of A from IN

European market for fuel Indian market for fuel Conv. fuel prod. from Europe Conv. fuel prod. from India Synth. fuel prod. from India

$\mathrm{CO}_{2}$ $\mathrm{NO}_{\mathrm{x}}$
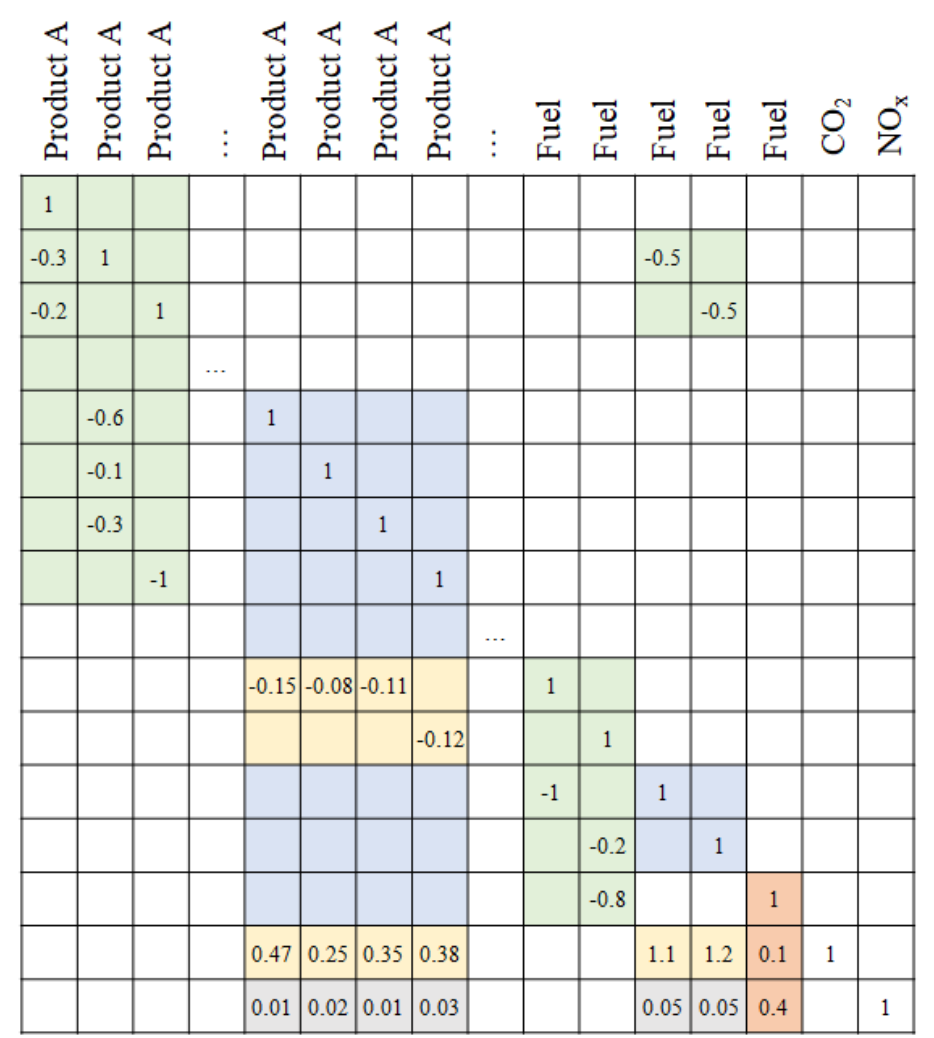

b) Simplified representation of transformations operated on the LCI database (positive values represent outputs, negative values represent inputs).

Figure 2 Schematic representation of transformations operated by premise premise follow the above-described principle to integrate IAM scenario data that relate to the following sectors:

- electricity generation: regional markets for biomass and electricity, efficiency update of power plants (including photovoltaic panels)

- $\quad$ steel and cement production: regional markets for primary and secondary steel, as well as cement, and efficiency update of primary and secondary steel and clinker production

- liquid and gaseous fuels production: regional markets for fuels (including biomass-based and synthetic fuels), $\mathrm{CO}_{2}$ emissions update of fuel-consuming activities

- road transport: regional fleet average vehicles, notably medium- and heavy-duty trucks

For a detailed description of the approach used for each of these sectors, the reader should refer to the documentation of the tool [26]. 
Re-submitted to Renewable and Sustainable Energy Reviews on February ${ }^{1 \text { st }}, 2022$.

As the following results section shows, the sector-wide transformations described above may lead to remarkable changes in the database, more even so as a few key activities, such as the provision of electricity or freight transport, provide inputs to a large number of activities.

\section{Results}

Section 3.1 starts with presenting the effect of the different climate change mitigation targets relative to the original LCI database, as transformations are incrementally performed. In Sections 3.2 and 3.3, the focus is set on the effect of such transformations on a few specific activities in the database over time and across climate change mitigation targets and locations. Finally, Section 3.4 compares the GHG emissions of a specific activity for one specific climate change mitigation target and year, but across different IAM scenarios. A last case study is presented in the Supplementary Information (SI) and shows the GHG emissions for the production of $1 \mathrm{~kg}$ of Li-NMC-622 battery cell. This case study is selected to demonstrate the importance of integrating metal recycling as well as the integration of other sub-sectors such as heat supply at a later stage of software development of premise.

3.1 The influence of climate change mitigation targets on energy- and material-intensive product systems

Using the IAM REMIND, Figure 3 illustrates the normalized effect of transformations applied to the LCI database considering three climate change mitigation targets for the year 2050: RCP 6.0, RCP 2.6 and RCP 1.9. Four cases are plotted to distinguish the effect of the transformation applied: (1) the electricity sector only, (2) the electricity and fuel sectors (3), the electricity, fuel and cement sectors, and (4) all sectors, which adds, among others, medium and heavy-duty trucks. An LCA has been performed on the database activities to obtain their unitary GHG emissions using the impact assessment method (IPCC 2013 GWP100a, including biogenic carbon, as provided in [51]). Market and treatment activities are excluded to avoid double counting in the cumulative sum. The horizontal axis shows the number of activities included. Impacts are normalized by the cumulative GHG emissions of the reference database ecoinvent v.3.8, for which the sum is denoted by ' 1 ' (or $100 \%$ ). This allows comparing the carbon intensity of the database across sector transformations. Updating the Electricity sector (1) with variables given by the RCP 1.9 scenario in 2050 results in a sum of cumulative GHG emissions $61 \%$ lower than that of the reference database. Note that steep increases along those curves are caused 
by a few activities that have a large carbon footprint, such as the construction of port facilities, hydropower plants as well as airports, respectively.

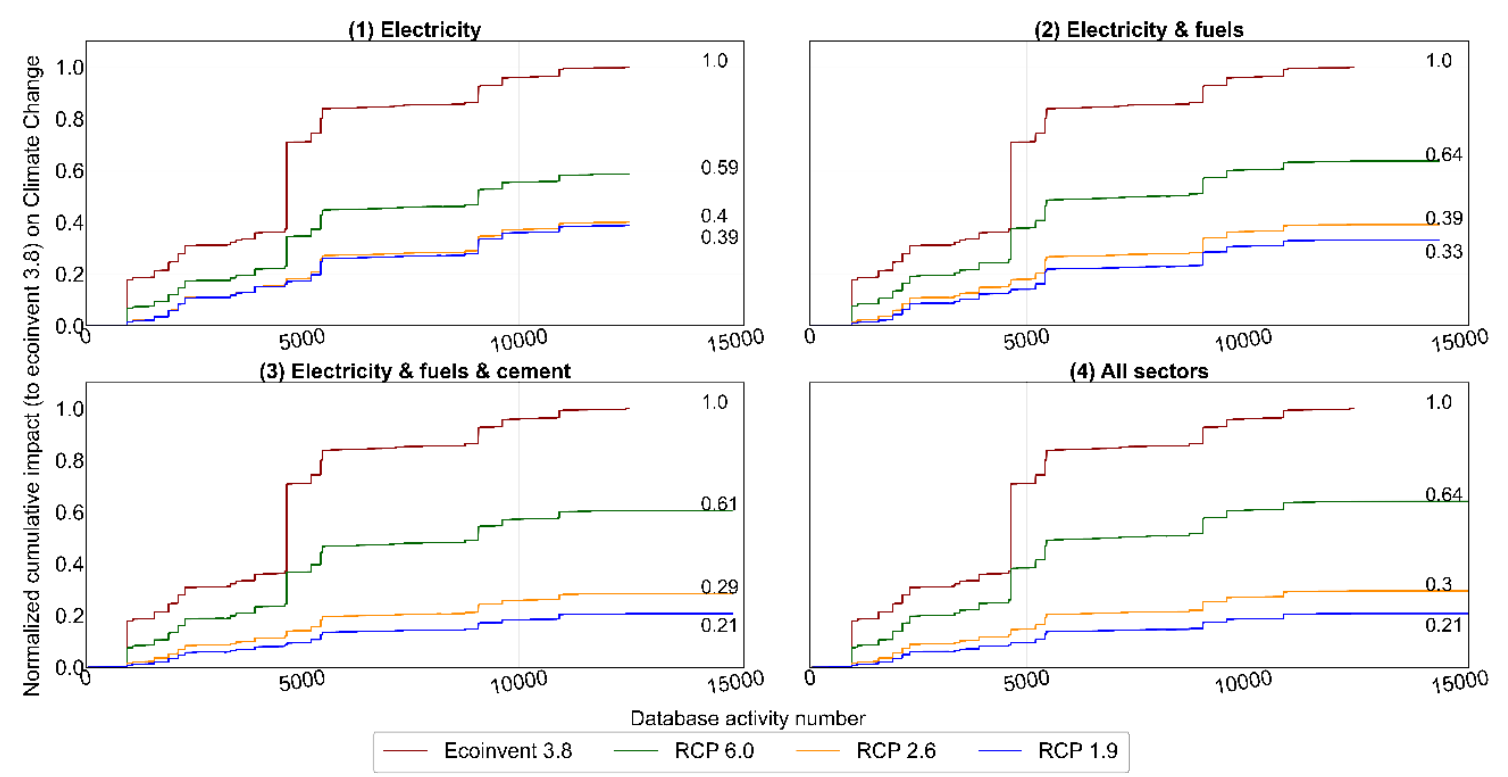

Figure 3 Cumulative sum of GHG emissions across activities in ecoinvent, for several climate change mitigation targets, in 2050, using the IAM REMIND

Specific sector integrations can have a significant impact for individual activities or some sector-related product systems. Interestingly, the choice in terms of climate change mitigation targets also has a large influence on the results. While the scenario using the climate change mitigation target RCP 6.0 reduces the sum of GHG emissions of the database by a third in 2050 considering all sector transformations, the more stringent scenario using RCP 1.9 leads to a reduction of about $80 \%$ that same year. It is worth noting that the relative difference in results between scenarios RCP 2.6 and 1.9 is negligible by 2050 in panel 1 of Figure 3, but it becomes more pronounced when regional fuel markets are introduced, as panel 2 shows. In the RCP 1.9 scenario of REMIND, the use of woody biomass-based and synthetic fuels (from gasified biomass) represent more than $50 \%$ of the energy consumed as liquid fuel globally, leading to significant reductions in $\mathrm{CO}_{2}$ emissions, while that share reaches only $16 \%$ in the RCP 2.6 scenario.

\subsection{Road construction}

Using again REMIND scenarios, this section analyzes the effect of two parameters on the GHG emissions of road infrastructure over time: an increasingly stringent climate change target in the prospective scenario, as well as the incremental application of sector-wide transformations in the pLCI database. Figure 4 illustrates the GHG 
emissions associated with the construction of one meter of a road, full width, normalized by its lifetime (name of the dataset: road construction, unit: meter-year, region: Rest of the World) for four different years - 2020, 2030, 2040 and 2050 - across the three different climate change mitigation targets. Again, the four subplots present different transformations of specific sectors as explained in the previous paragraphs. The bar plots also show the contribution of different components in the total GHG emissions of a meter-year of road.

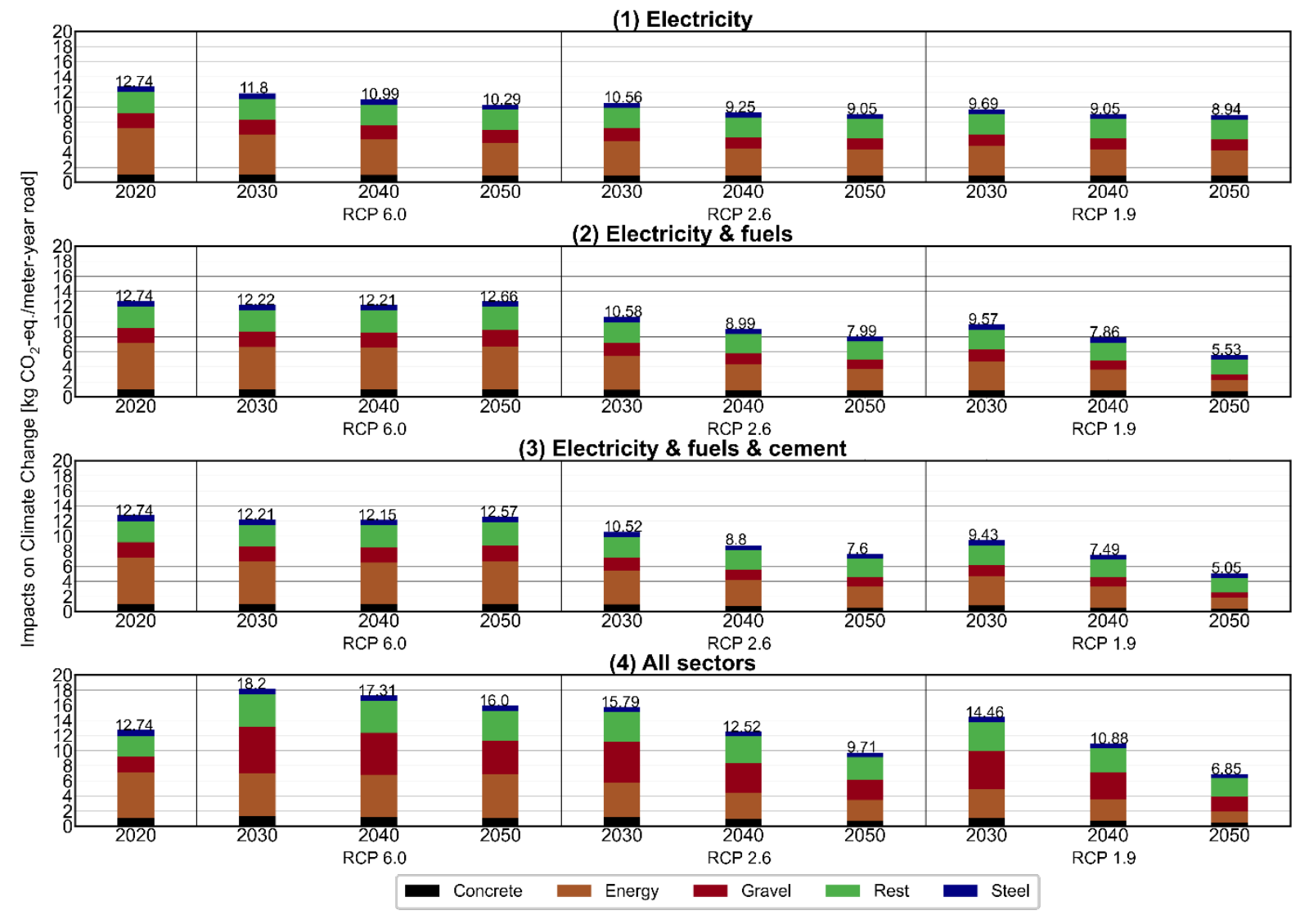

Figure 4 GHG emission for the construction of one meter-year of road sector transformations, for different years and climate change mitigation targets

The reference (static) GHG emissions for the construction of 1 meter-year of road is $12.7 \mathrm{~kg} \mathrm{CO}$-eq. in 2020.

The de-carbonization of the power system between 2020 and 2050 in the RCP6 scenario leads to a $20 \%$ reduction in GHG emissions, and changing from RCP 6 to RCP 1.9 for that same year leads to another reduction of more than $10 \%$ in GHG emissions. However, results also indicate that aligning the fuel markets and composition in the pLCI database with the IAM scenario has the largest influence on the GHG emissions of road construction by 2050 . Indeed, an additional 40\% GHG emission reduction in 2050 in the RCP 1.9 scenario is observed, as the share of biomass-based fuels in the global liquid fuel mix goes from 1\% in 2020 to $54 \%$ in 
Re-submitted to Renewable and Sustainable Energy Reviews on February ${ }^{1 \text { st }}, 2022$.

2050. This underlines the importance of not limiting pLCA to the integration of changes in the sector of power generation, as previous studies have done. The transformations applied on the cement sector lead to an additional reduction in GHG emissions of about 10\% using RCP 1.9 climate mitigation target, compared to the integration of the electricity and fuel sectors. This is mainly due to three mechanisms: the utilization of cement in concrete with a lower clinker content, an improved clinker kiln efficiency as well as the capture of both process and fuel $\mathrm{CO}_{2}$ emissions. Overall, between 2020 and 2050 in the RCP 1.9 scenario, the clinker-to-cement ratio drops for all regions by $13 \%$ on average (they start at different levels across regions), the fuel efficiency of the kiln increases from between 30 to $50 \%$ depending on the region, and the rate of carbon capture ranges between 65 and $75 \%$ by then. The integration of all sectors in 2050 using RCP 1.9 leads to reducing GHG emissions by a fourth (compared to integrating transformations associated to the electricity sector only). Interestingly, not all sector transformations lead to a reduction in GHG emissions. For all scenarios, the transformations of the electricity, fuel, steel and cement sectors reduce the overall GHG emissions as expected, while the transformation of the road transport sector increases them. More specifically in this case, the transformation of the transport sector increases GHG emissions from the "Gravel" supply. This is explained by the gravel being transported by a less performant fleet average heavy-duty vehicle than initially modeled in the reference database. This is due to the combined effects of: (1) premise introducing heavy-duty trucks with a lower load factor than those originally present in ecoinvent (i.e., 9.1 tons of cargo transported against 16 tons for $>32 \mathrm{t}$ trucks in ecoinvent), (2) a regional, but fuel-intensive, driving cycle applied for shorter distances, as well as (3) the electrification of the fleet supplied with electricity that is not de-carbonized enough (in the case of the RCP 6 scenario).

\subsection{Direct Air Carbon Capture and Storage}

Using the REMIND model, the performance of atmospheric removal of carbon is analyzed across different climate change targets as well as geographical contexts. Figure 5 illustrates the life-cycle GHG emissions for the capture of 1 ton $\mathrm{CO}_{2}$ from ambient air with its subsequent storage, referred to as DACCS. It uses the regional grid electricity as an energy source to operate the process, including a heat pump to provide the necessary heat with a CoP of 2.9, as described in [52]. Two subplots and database transformations are considered; (1) transformations of the electricity and fuel sectors, and (2) transformations of all sectors, as this specific product system is relatively energy-intensive. A negative climate change impact on the vertical axis indicates the net permanent removal of $\mathrm{CO}_{2}$ from the atmosphere - i.e., the amount of $\mathrm{CO}_{2}$ sequestered from which various $\mathrm{GHG}$ emissions that result from the life cycle of the DACCS system are subtracted. The secondary vertical axis shows 
the corresponding $\mathrm{CO}_{2}$ removal effectiveness. Six geographical regions are included - Japan, Latin America, Europe, the United States, China and India - to show the region-specific climate change impacts of DACCS deployment.

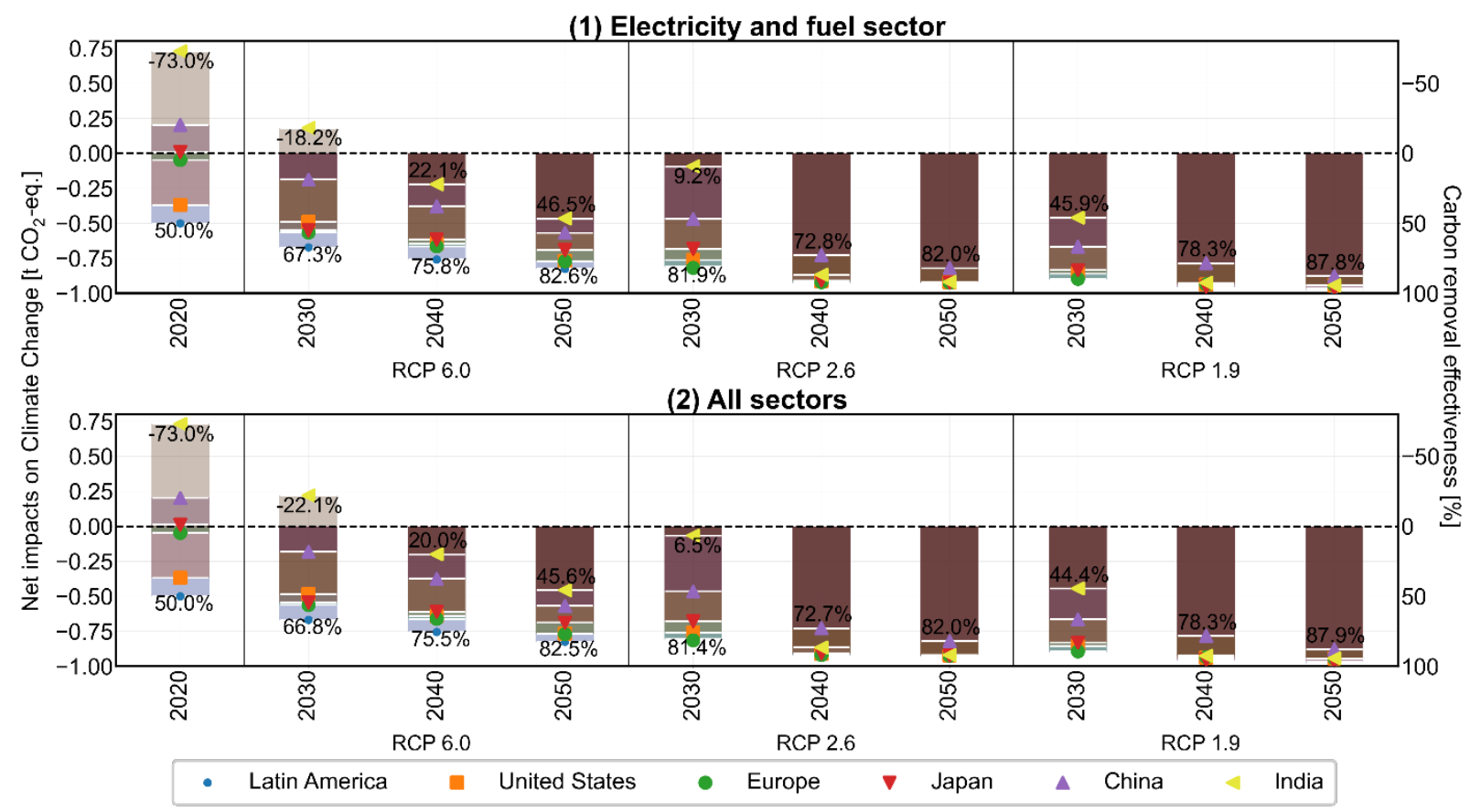

Figure $5 \mathrm{Net}$ GHG emissions for the capture and storage of 1 ton of $\mathrm{CO}_{2}$ from the atmosphere, using DACCS, for different IAM regions, years and climate change mitigation targets

The comparison between the upper and lower panels of Figure 5 indicates very small differences between the transformations of (1) the electricity and fuel sectors and of (2) all sectors, on the climate change impacts of DACCS deployment. The life cycle climate change impacts of DACCS are largely driven by the GHG-intensity of energy sources needed for $\mathrm{CO}_{2}$ capture; a substantial amount of grid electricity is for example required for grid-coupled DACCS systems [52], especially as the case presented produces the heat needed to re-generate the solid sorbent via a heat pump. DACCS deployment in geographical regions with GHG-intensive electricity supply and the integration of the electricity sector of a specific IAM scenario have an important influence on the total climate change Impacts (or carbon removal effectiveness). The most stringent climate change mitigation scenario RCP 1.9 has, for example, a minimum carbon removal effectiveness of $85-90 \%$ in 2050 - mainly due to the de-carbonization of the electricity sector - against only $45-50 \%$ for the RCP 6 scenario, leaving room for variation across geographical regions. Regions with a GHG-intensive electricity supply (e.g., India and China) exhibit a very low carbon removal effectiveness compared to regions with a cleaner electricity supply, such as 
Re-submitted to Renewable and Sustainable Energy Reviews on February ${ }^{1 \text { st }}, 2022$.

Latin America and Europe. In fact, under the wrong conditions, the operation can exhibit a net positive sum (e.g., see India in 2020 and 2030, under the RCP 6 target). First, this implies that grid-coupled DACCS systems are only suitable in geographical regions with clean electricity supply. Second, more ambitious climate policies will increase the carbon removal efficiency of grid-coupled DACCS. Both findings are in line with the work of Terlouw et al. [52].

\subsection{Convergence and divergence of results between IAM}

Figure 6 illustrates the relative change in climate change impacts - normalized to the reference database ecoinvent v.3.8 - with respect to four activities; (1) clinker production (in the United States), (2) medium voltage electricity supply (global average), (3) low-alloyed steel production (global average) and (4) transportation with a heavy duty vehicle (European fleet average). The analysis uses the three climate change mitigation scenarios as used previously, to compare results from IMAGE (green lines) to those of REMIND (yellow lines) from 2020 to 2050.

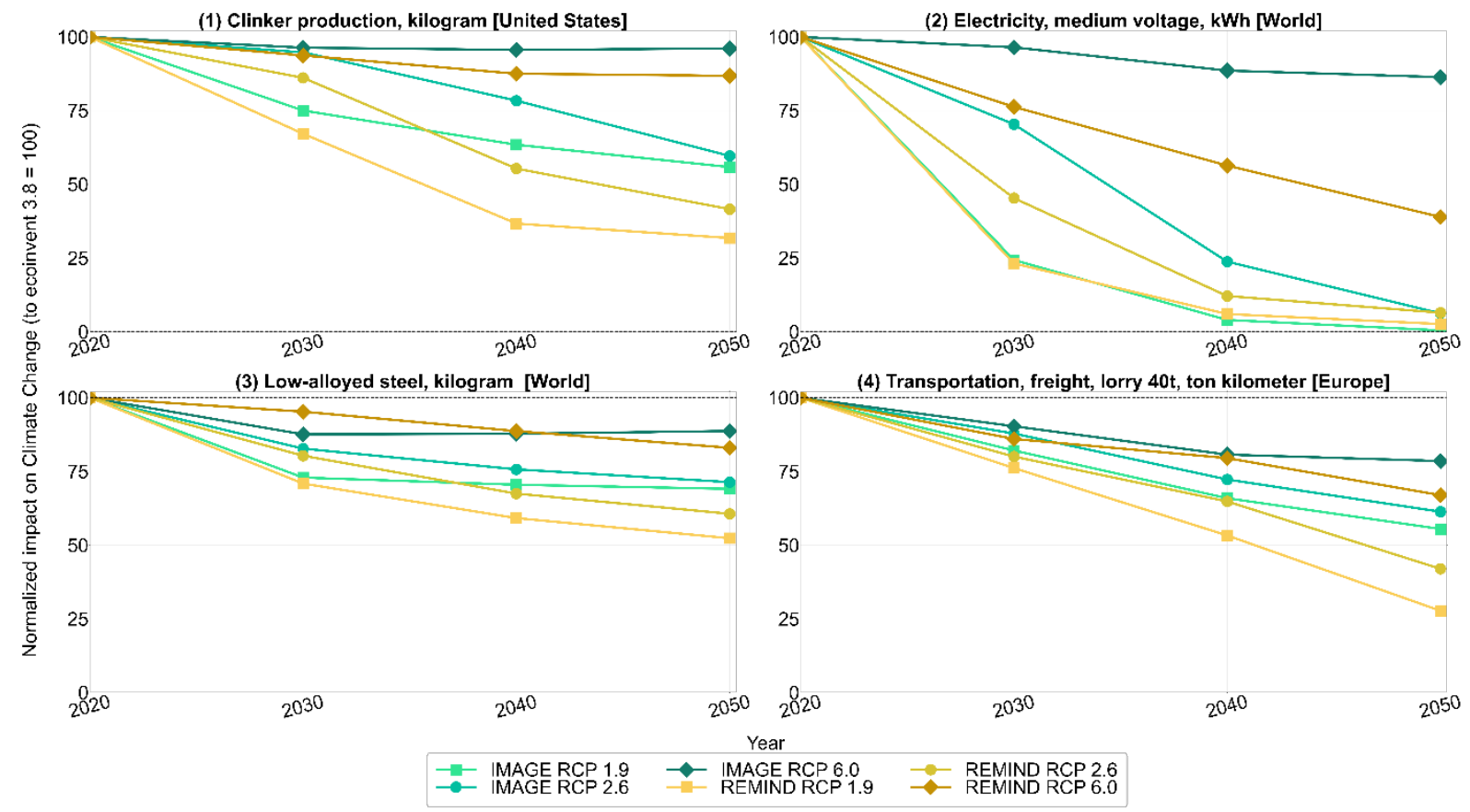

Figure 6 Relative change in GHG emissions for different products and services compared to 2020, across years and climate change mitigation targets, for REMIND and IMAGE, all sectorial transformations considered Regarding emissions levels in 2050 using the RCP 6 climate change mitigation target, REMIND and IMAGE roughly agree in respect to clinker production, steel production and heavy-duty transport, but much less so about electricity production. The divergence regarding the production of global average electricity, which is a market 
Re-submitted to Renewable and Sustainable Energy Reviews on February ${ }^{\text {st }}, 2022$.

that consists of a production volume-weighted electricity mix from the different IAM regions, is explained by the extent to which renewable sources of energy are used in RCP 6: they represent $60 \%$ of the production mix that year in REMIND, against $21 \%$ only in IMAGE. It is worth noting that neither REMIND nor IMAGE consider the use of CCS in any sectors for that climate change mitigation target. Looking at the RCP 1.9 climate change mitigation target, all activities calculated with the REMIND scenario scores consistently lower, except for electricity, where both models indicate an almost complete de-carbonization of the electricity production. The respective global production mixes chosen by the IAM models differ for 2050: while REMIND relies extensively on renewable sources of energy (90\%, when summing hydropower, photovoltaic and wind power), IMAGE relies comparatively more on combustion-based technologies (56\%), as well as renewables and nuclear power representing $31 \%$ and $11 \%$, respectively. CCS is applied to $64 \%$ of the electricity production involving a combustion process, $20 \%$ of which is applied on biomass-based power generation (i.e., BECCS), leading to net negative GHG emissions. Regarding heavy-duty transport, the numbers presented here change over time as a result of the combination of several dynamics. First, the drivetrain efficiency and onboard energy storage for the different powertrains constituting the trucks fleet change over time. Second, the fuel and electricity regional markets that sustain the operational phase of the trucks also change over time. Lastly, the change in the fleet composition, in terms of size class and powertrain types is also considered. The share of kilometers driven by European battery and fuel cell electric trucks reaches 51\% in 2050 in the REMIND scenarios (i.e., those shares do not differ across RCP). Hence, the difference in the carbon-intensity of the regional electricity mix used to sustain the operation of these trucks explains in part the difference between the RCP 6 and RCP 1.9 scenario results. The other part is explained by the share of alternative fuels in the regional diesel market between the two scenarios: $26 \%$ in the RCP 6 scenario, against $58 \%$ in the RCP 1.9 scenario. While battery electric freight vehicles are not modelled in IMAGE scenarios, fuel cell electric and plugin hybrid electric trucks constitute $94 \%$ of the kilometers driven in 2050 . Here, the difference in use of alternative fuels between the two scenarios is less pronounced: $6 \%$ in the RCP 6 scenario, against $15 \%$ in the RCP 1.9 scenario. This underlines the influence the scenario-specific regional electricity mix has on the performance of the transport of heavy goods by road, together with the penetration of alternative liquid fuels.

While both electricity mixes are part of a solution that is bound to reach the same climate change mitigation target, the effect on indicators other than climate change can differ. Using midpoint indicators from the impact assessment method ReCiPe 2008 v.1.13, Figure 7 displays the evolution over time of the impact of low voltage 
global electricity supply in the RCP 1.9 scenario. The $\mathrm{x}$-axis presents the year of assessment, while the y-axis indicates the characterized impact normalized by the impact of the same activity in 2020 .

As expected, both model scenarios result in much lower impacts on climate change: $-106 \%$ and $-98 \%$ for IMAGE and REMIND in 2050, respectively, with respect to 2020. The negative change in climate change impacts for the IMAGE scenario (i.e., -106\%) is explained by the use of BECCS which represents more than $10 \%$ of gross global production mix in 2050 (see Figure 7.b), resulting in a net permanent carbon removal.

However, the associated environmental trade-offs are different between the two scenarios. In both models, the reduction of GHG emissions comes with an increase in other types of impacts, such as agricultural and urban land occupation as well as terrestrial eco-toxicity and emissions of stratospheric ozone-depleting gases. More specifically, the IMAGE scenario relies on high capacities of conventional generators (mainly natural gas) and biomass generators, both with CCS (see Figure 7.b), while the REMIND scenario relies on high shares of renewable electricity generation, such as photovoltaics in built environments and wind-based electricity supply. Both scenarios result in a significant increase of Land Occupation, whether it be agricultural in the case of the IMAGE scenario (i.e., provision of "purpose grown" biomass, despite $61 \%$ of all the biomass used for power generation being supplied by agricultural and forestry residues), or a mix of agricultural and urban land in the case of the REMIND scenario (i.e., open-ground photovoltaics installations).

Also, while both scenarios reduce impacts related to fossil fuel use, the IMAGE scenario still relies to some extent on fossil energies in 2050, leading to the emission of ozone-depleting gases (see Ozone depletion indicator), since a high capacity of conventional generators (mainly natural gas-fired combined-cycle and CHP power plants) is maintained in combination with CCS. This occurs because of emissions of Halon gases along the supply chain of natural gas to the power plants. The REMIND scenario, however, exhibits higher impacts in terms of terrestrial eco-toxicity, mainly stemming from the production of commercial photovoltaic panels and wind turbines. Two reasons are identified. First, the requirement in terms of road transport for photovoltaic panels and wind turbines is high. This leads to toxic metal emissions coming from brake and tire abrasion (e.g., cadmium, copper). Combined to the important share of biodiesel from energy crops in the regional diesel market, it also leads to a significant use of insecticide (e.g., cypermethrin) to grow the necessary crops - it can however be argued that the extent and toxicity of insecticide use in the future may be reduced, which is something neither premise nor IAM consider. Second, the emissions of fine metal particles (e.g., lead, tin and silver) during the manufacture of photovoltaic cells eventually deposit on the surrounding land. It is also worth 
Re-submitted to Renewable and Sustainable Energy Reviews on February 1 ${ }^{\text {st }}, 2022$.

noting that both scenarios increase the strain on metal reserves, notably rare earths, although the differences between the two scenarios are small. Future dynamics in terms of metals recycling are not considered by premise at the moment - hence these numbers are probably overestimating the future use of metals. Finally, nuclear-based electricity generation is maintained to a large extent in the IMAGE scenario (between $16 \%$ and $20 \%$ of the gross production mix in the future, against $11 \%$ today), explaining the increased emissions of ionizing radiation.

These results imply that each scenario requires a thorough assessment of environmental trade-offs and cobenefits associated to reaching a de-carbonized economy in the future. These additional indicators could prove useful in the future for designing climate change mitigation scenarios. 


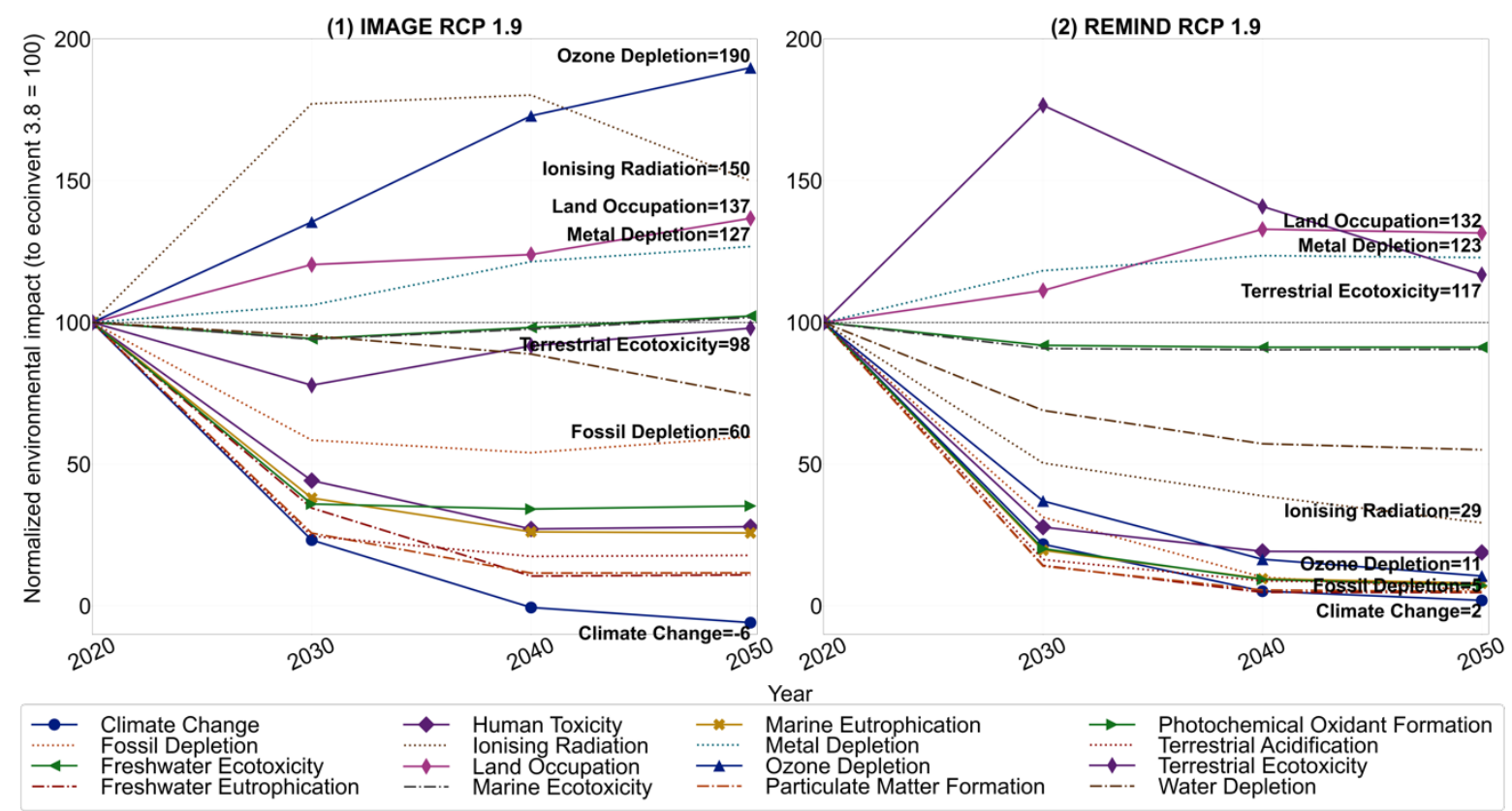

a) Change relative to 2020 for several midpoint indicators for the provision of low voltage electricity, global average, across years, for the SSP 2-RCP 1.9 scenario, for IMAGE (left) and REMIND (right).

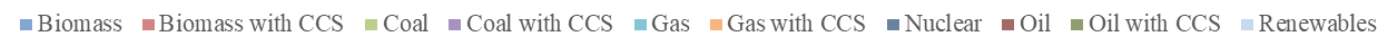

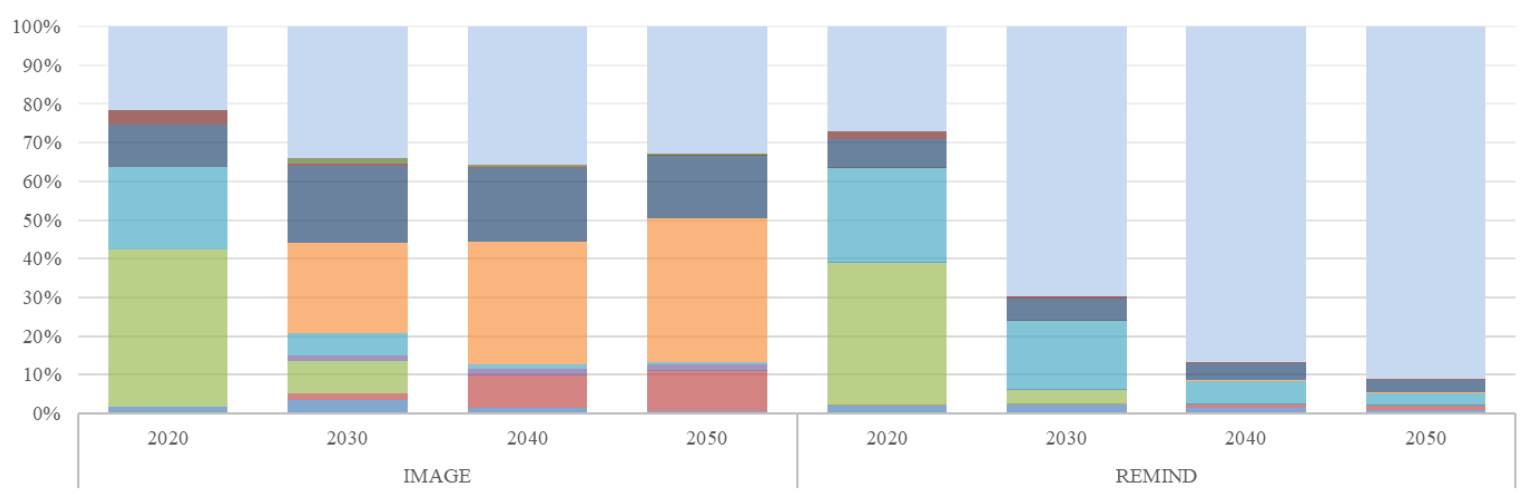

b) Gross global electricity production mix, across years, for the SSP 2-RCP 1.9 scenario, for IMAGE (left) and REMIND (right). Technologies are aggregated by type of energy carrier.

Figure 7 Relative changes in midpoint indicators relative to 2020 (a) and corresponding gross production mix (b)

\section{Discussion}

Some aspects that relate to the challenges faced when coupling and finding a common terminology between IAM scenarios with LCA, but also the purpose and future use cases of such exercise, are discussed in this section. 


\subsection{Limitations}

The largest challenge in coupling IAM and LCA is the potential mismatch between the modeled technologies in IAM and in the corresponding life-cycle inventories. In order to reduce the computational complexity, IAM group similar technologies and assign generic properties to them based on historical information. They also cluster regions spatially based on their location and socio-economic properties. Life-cycle inventories have no computational constraints and strive to be as detailed and differentiated between technologies and geographic scopes as possible. The discrepancy in data granularity might lead to semantic ambiguity, where an IAM process could have one or multiple corresponding activities with unspecified shares in the LCI database. A typical example would be the lack of a distinction based on grades for steel products in the IAM, while such distinction has a significant importance in terms of material and energy inventory in the LCI database. It could also lead to semantic mismatch, for example if the region "Europe" has a different geographical definition for the IAM and for the LCI database. While these discrepancies cannot be alleviated completely without altering the resolution of the IAM and/or the LCI database, it is possible to minimize their impact through a proper understanding and a correct interpretation of the data on both sides. The use of transparent mapping files, described in the tool's documentation [26], that link the variables between models can help, if not to solve such ambiguities, to better trace them back.

Also, for some transformations, premise relies at the moment on external data sources, such as the GAINS model for the projections on the reduction of non- $\mathrm{CO}_{2}$ emissions, but also on inventories from the LCA literature for various emerging technologies. This can potentially introduce modelling inconsistencies as indicated also in the premise documentation [26].

Furthermore, there is also a temporal constraint: while IAM provide projections up to 2100 , it seems difficult to extend reliably the coupling between IAM and LCA beyond 2050-2060. While the LCI database can accommodate incremental shifts in efficiency, which is what premise does, it cannot anticipate potentially disruptive shifts in technologies (e.g., nuclear fusion).

Finally, results given for toxicity-related indicators (e.g., human toxicity, terrestrial toxicity, ecosystems toxicity) should be regarded as highly uncertain, especially when those increase or become important when normalized. Such case appears with the use of pesticide to produce biodiesel described in the previous section. IAM do not carry any information regarding the use, fate or toxicity of chemicals in the future, and scaling the use of current chemicals up or down as premise currently does can be misleading. 


\subsection{Integrating IAM projections into LCA: a means to a larger goal?}

The results have shown the effects of integrating IAM projections into the LCI database, by contrasting results calculated with the static ecoinvent database v3.8 to those derived from the coupling. Unlike a scenario-based pLCA relying on independent assumptions, the use of the IAM provides a coherent narrative, balancing the global perspective with the regional singularities. The benefits for IAM are equally unequivocal: through the LCA coupling, it is possible to quantify impacts that are not directly modeled in the IAM, such as impacts on human health and ecosystems, land use or metal depletion. Hence, without affecting the computational complexity of the IAM or straying away from the objective of system de-carbonization, it is possible to quantify the environmental side effects of different scenarios. Ultimately, it may be possible to feed the LCA impacts back into the IAM, for instance by monetizing them and recalculating the cost-optimal solution in an iterative process, or by introducing additional constraints. This has the potential to provide a holistic approach to the system transformation, anticipate resource bottlenecks and environmental criticalities, and identify transformation strategies accounting for multiple environmental goals.

\subsection{Next steps}

The open-source library premise is continuously improved, with new features expected in the short and midterm. The addition of new sectors - heat supply, extraction, refining and recycling of metals, and negative $\mathrm{CO}_{2}$ emission technologies - will expand its functionality. Also, the foreseeable dominance of renewable energy sources in the projected electricity mixes highlights the necessity to improve inventories of renewable power plants, such as photovoltaic panels and wind turbines, in particular their efficiency and load factor, which are only rudimentarily represented in ecoinvent. Currently, premise only adjusts the efficiency of photovoltaic panels by modifying the panel surface needed per kilowatt of peak power capacity installed. But ultimately, parametrized models such as those developed in [53,54] for wind turbines and [55] for photovoltaic panels will be needed to create region and year-specific inventories.

Furthermore, new collaborations with other IAM are sought after in order to develop an interface to additional models. In addition, substantial efforts are channeled into improved reporting. Ultimately, a fully detailed report should be generated with each pLCI database produced, to indicate all the changes made as well as the boundary conditions behind the scenario narrative and climate change mitigation target used by the IAM. 


\section{Conclusion}

As commitments to curb emissions of greenhouse gases accelerate, rapid transformations are expected in energy systems and industries. This makes prospective LCA useful to assess the environmental performance of quickly developing, but also emerging or yet-to-be-developed technologies. This study shows that it is possible to streamline the production of comprehensive pLCI databases in order to facilitate the development and increase the quality of pLCA studies. It also shows that the scenario narrative chosen as well as the selected IAM and its specific way of achieving climate change mitigation goals can have significant effects on the LCI database (and thereby any foreground model that relies on it). There is therefore some critical uncertainty in any LCA study using such databases, as the de-carbonization pathway and the actual technological breakthroughs are unknown. However, premise allows to have a broad idea on the effect such uncertainty can have on the LCI database as comparing a multitude of scenario-specific databases is made easy.

\section{CRediT author statement}

Romain Sacchi: Methodology, Software, Writing - Original Draft, Alois Dirnaichner: Methodology, Software, Christopher L. Mutel: Methodology, Software, Christian Bauer: Supervision, Writing - Review \& Editing,

Brian L. Cox: Conceptualization, Writing - Review \& Editing, Vassilis Daioglou: Writing - Review \& Editing, Tom Terlouw: Software, Visualization, Kais Siala: Writing - Review \& Editing, Gunnar Luderer: Supervision, Writing - Review \& Editing

\section{Acknowledgement}

The authors would like to thank Angélica Mendoza Beltrán and Laurent Vandepaer for their early contribution and discussions around the topic of IAM-LCA integration.

\section{Funding sources}

This work has partially received financial support from the Kopernikus Project Ariadne (FKZ 03SFK5A), funded by the German Federal Ministry of Education and Research.

\section{Data availability}

The tool presented in this study as well as its source code are available in the following repository: 


\section{References}

[1] van der Giesen C, Cucurachi S, Guinée J, Kramer GJ, Tukker A. A critical view on the current application of LCA for new technologies and recommendations for improved practice. J Clean Prod 2020;259:120904. https://doi.org/10.1016/j.jclepro.2020.120904.

[2] van der Giesen C, Cucurachi S, Guinée J, Kramer GJ, Tukker A. A critical view on the current application of LCA for new technologies and recommendations for improved practice. J Clean Prod 2020;259:120904. https://doi.org/10.1016/J.JCLEPRO.2020.120904.

[3] Thonemann N, Schulte A, Maga D. How to Conduct Prospective Life Cycle Assessment for Emerging Technologies? A Systematic Review and Methodological Guidance. Sustain 2020, Vol 12, Page 1192 2020;12:1192. https://doi.org/10.3390/SU12031192.

[4] Bisinella V, Christensen TH, Astrup TF. Future scenarios and life cycle assessment: systematic review and recommendations. Int J Life Cycle Assess 20212611 2021;26:2143-70. https://doi.org/10.1007/S11367-021-01954-6.

[5] Thomassen G, Van Passel S, Dewulf J. A review on learning effects in prospective technology assessment. Renew Sustain Energy Rev 2020;130:109937.

https://doi.org/10.1016/J.RSER.2020.109937.

[6] Arvidsson R, Tillman AM, Sandén BA, Janssen M, Nordelöf A, Kushnir D, et al. Environmental Assessment of Emerging Technologies: Recommendations for Prospective LCA. J Ind Ecol 2018;22:1286-94. https://doi.org/10.1111/JIEC.12690.

[7] Moni SM, Mahmud R, High K, Carbajales-Dale M. Life cycle assessment of emerging technologies: A review. J Ind Ecol 2020;24:52-63. https://doi.org/10.1111/JIEC.12965.

[8] Gibon T, Wood R, Arvesen A, Bergesen JD, Suh S, Hertwich EG. A Methodology for Integrated, Multiregional Life Cycle Assessment Scenarios under Large-Scale Technological Change. Environ Sci Technol 2015;49:11218-26. https://doi.org/10.1021/acs.est.5b01558.

[9] Frischknecht R, Jungbluth N, Althaus HJ, Doka G, Dones R, Heck T, et al. The ecoinvent database: Overview and methodological framework. Int J Life Cycle Assess 2005;10:3-9.

https://doi.org/10.1065/lca2004.10.181.1.

[10] Arvesen A, Luderer G, Pehl M, Bodirsky BL, Hertwich EG. Deriving life cycle assessment coefficients for application in integrated assessment modelling. Environ Model Softw 2018;99:111-25. https://doi.org/10.1016/j.envsoft.2017.09.010.

[11] Pehl M, Arvesen A, Humpenöder F, Popp A, Hertwich EG, Luderer G. Understanding future emissions from low-carbon power systems by integration of life-cycle assessment and integrated energy modelling. Nat Energy 2017;2:939-45. https://doi.org/10.1038/s41560-017-0032-9.

[12] Aboumahboub T, Auer C, Bauer N, Baumstark L, Bertram C, Bi S, et al. Model Documentation | Version 2.1.0 | REMIND - REgional Model of INvestments and Development 2020. https://doi.org/10.5281/ZENODO.3730919.

[13] Luderer G, Pehl M, Arvesen A, Gibon T, Bodirsky BL, de Boer HS, et al. Environmental co-benefits and adverse side-effects of alternative power sector decarbonization strategies. Nat Commun 2019;10:113. https://doi.org/10.1038/s41467-019-13067-8.

[14] Mendoza Beltran A, Cox B, Mutel C, van Vuuren DP, Font Vivanco D, Deetman S, et al. When the Background Matters: Using Scenarios from Integrated Assessment Models in Prospective Life Cycle Assessment. J Ind Ecol 2018;24:64-79. https://doi.org/10.1111/jiec.12825.

[15] Cox B, Mutel CL, Bauer C, Mendoza Beltran A, Van Vuuren DP. Uncertain Environmental Footprint of Current and Future Battery Electric Vehicles. Environ Sci Technol 2018;52:4989-95. https://doi.org/10.1021/acs.est.8b00261.

[16] Cox B, Bauer C, Mendoza Beltran A, van Vuuren DP, Mutel CL. Life cycle environmental and cost comparison of current and future passenger cars under different energy scenarios. Appl Energy 2020;269:115021. https://doi.org/10.1016/j.apenergy.2020.115021.

[17] Stehfest E, Vuuren D van, Kram T, Bouwman L, Alkemade R, Bakkenes M, et al. Integrated Assessment of Global Environmental Change with IMAGE 3.0. Model description and policy applications. 2014.

[18] Mercure JF, Pollitt H, Edwards NR, Holden PB, Chewpreecha U, Salas P, et al. Environmental impact assessment for climate change policy with the simulation-based integrated assessment model E3MEFTT-GENIE. Energy Strateg Rev 2018;20:195-208. https://doi.org/10.1016/j.esr.2018.03.003.

[19] Knobloch F, Hanssen S V., Lam A, Pollitt H, Salas P, Chewpreecha U, et al. Net emission reductions from electric cars and heat pumps in 59 world regions over time. Nat Sustain 2020;3:437-47. https://doi.org/10.1038/s41893-020-0488-7.

[20] Rauner S, Bauer N, Dirnaichner A, Dingenen R Van, Mutel C, Luderer G. Coal-exit health and 
Re-submitted to Renewable and Sustainable Energy Reviews on February ${ }^{\text {st }}, 2022$.

environmental damage reductions outweigh economic impacts. Nat Clim Chang 2020;10:308-12. https://doi.org/10.1038/s41558-020-0728-x.

[21] Harpprecht C, van Oers L, Northey SA, Yang Y, Steubing B. Environmental impacts of key metals' supply and low-carbon technologies are likely to decrease in the future. J Ind Ecol 2021;25:1543-59. https://doi.org/10.1111/JIEC.13181.

[22] Dirnaichner A, Rottoli M, Sacchi R, Rauner S, Cox B, Mutel CL, et al. Life-cycle impacts from different decarbonization pathways for the European car fleet. Environ Res Lett 2022. https://doi.org/10.1088/1748-9326/ac4fdb.

[23] Rottoli M, Dirnaichner A, Kyle P, Baumstark L, Pietzcker R, Luderer G. Coupling a Detailed Transport Model to the Integrated Assessment Model REMIND. Environ Model Assess 2021;1:3. https://doi.org/10.1007/s10666-021-09760-y.

[24] Wernet G, Bauer C, Steubing B, Reinhard J, Moreno-Ruiz E, Weidema B. The ecoinvent database version 3 (part I): overview and methodology. Int J Life Cycle Assess 2016;21:1218-30. https://doi.org/10.1007/s11367-016-1087-8.

[25] Joyce PJ, Björklund A. Futura: A new tool for transparent and shareable scenario analysis in prospective life cycle assessment. J Ind Ecol 2021. https://doi.org/10.1111/JIEC.13115.

[26] Sacchi R. User guide — premise 1.0.0 documentation 2022. https://premise.readthedocs.io/en/latest/ (accessed January 24, 2022).

[27] Mutel CL. Introduction - wurst 0.1 documentation 2017. https://wurst.readthedocs.io/ (accessed April 25, 2021).

[28] Steubing B, de Koning D, Haas A, Mutel CL. The Activity Browser - An open source LCA software building on top of the brightway framework. Softw Impacts 2020;3:100012.

https://doi.org/10.1016/j.simpa.2019.100012.

[29] Steubing B, de Koning D. Making the use of scenarios in LCA easier: the superstructure approach. Int J Life Cycle Assess 2021;26:2248-62. https://doi.org/10.1007/S11367-021-01974-2/FIGURES/7.

[30] Weyant J. Some Contributions of Integrated Assessment Models of Global Climate Change ". Rev Environ Econ Policy 2017;11:115-37. https://doi.org/10.1093/reep/rew018.

[31] Nordhaus W. Estimates of the Social Cost of Carbon: Concepts and Results from the DICE-2013R Model and Alternative Approaches. J Assoc Environ Resour Econ 2014;1:273-312. https://doi.org/10.1086/676035.

[32] Anthoff D, Tol RSJ. The uncertainty about the social cost of carbon: A decomposition analysis using fund. Clim Change 2013;117:515-30. https://doi.org/10.1007/s10584-013-0706-7.

[33] Baumstark L, Bauer N, Benke F. REMIND2.1: Transformation and innovation dynamics of the energyeconomic system within climate and sustainability limits. Geosci Model Dev Discuss 2021. https://doi.org/https://doi.org/10.5194/gmd-2021-85.

[34] Girod B, van Vuuren DP, de Vries B. Influence of travel behavior on global CO2 emissions. Transp Res Part A Policy Pract 2013;50:183-97. https://doi.org/10.1016/j.tra.2013.01.046.

[35] Levesque A, Pietzcker RC, Baumstark L, Luderer G. Deep decarbonisation of buildings energy services through demand and supply transformations in a $1.5^{\circ} \mathrm{C}$ scenario. Environ Res Lett 2021. https://doi.org/10.1088/1748-9326/abdf07.

[36] Daioglou V, van Ruijven BJ, van Vuuren DP. Model projections for household energy use in developing countries. Energy 2012;37:601-15. https://doi.org/10.1016/j.energy.2011.10.044.

[37] van Sluisveld M, de Boer HS, Daioglou V, Hof A, van Vuuren D. A race to zero - assessing the position of heavy industry in a global net-zero CO2 emissions context. Energy Clim Chang 2021.

[38] Daioglou V, Doelman JC, Wicke B, Faaij A, van Vuuren DP. Integrated assessment of biomass supply and demand in climate change mitigation scenarios. Glob Environ Chang 2019;54:88-101. https://doi.org/10.1016/j.gloenvcha.2018.11.012.

[39] Doelman JC, Stehfest E, Vuuren DP, Tabeau A, Hof AF, Braakhekke MC, et al. Afforestation for climate change mitigation: Potentials, risks and trade-offs. Glob Chang Biol 2020;26:1576-91. https://doi.org/10.1111/gcb.14887.

[40] Dietrich JP, Bodirsky BL, Humpenöder F, Weindl I, Stevanović M, Karstens K, et al. MAgPIE 4-a modular open-source framework for modeling global land systems. Geosci Model Dev 2019;12:1299_ 317. https://doi.org/10.5194/gmd-12-1299-2019.

[41] Bauer N, Klein D, Humpenöder F, Kriegler E, Luderer G, Popp A, et al. Bio-energy and CO2 emission reductions: an integrated land-use and energy sector perspective. Clim Change 2020;163:1675-93. https://doi.org/10.1007/s10584-020-02895-z.

[42] Luderer G, Madeddu S, Merfort L, Ueckerdt F, Pehl M, Pietzcker R, et al. Impact of declining renewable energy costs on electrification in low-emission scenarios. Nat Energy 2021 2021:1-11. https://doi.org/10.1038/s41560-021-00937-z.

[43] Mouratiadou I, Bevione M, Bijl DL, Drouet L, Hejazi M, Mima S, et al. Water demand for electricity in 
deep decarbonisation scenarios: a multi-model assessment. Clim Change 2018;147:91-106. https://doi.org/10.1007/s10584-017-2117-7.

[44] Bijl DL, Biemans H, Bogaart PW, Dekker SC, Doelman JC, Stehfest E, et al. A Global Analysis of Future Water Deficit Based On Different Allocation Mechanisms. Water Resour Res 2018;54:5803-24. https://doi.org/10.1029/2017WR021688.

[45] O’Neill BC, Kriegler E, Riahi K, Ebi KL, Hallegatte S, Carter TR, et al. A new scenario framework for climate change research: The concept of shared socioeconomic pathways. Clim Change 2014;122:387400. https://doi.org/10.1007/s10584-013-0905-2.

[46] Hausfather Z. Explainer: How "shared socioeconomic pathways" explore future climate change. CarbonBrief 2018. https://www.carbonbrief.org/explainer-how-shared-socioeconomic-pathwaysexplore-future-climate-change (accessed April 25, 2021).

[47] Riahi K, van Vuuren DP, Kriegler E, Edmonds J, O’Neill BC, Fujimori S, et al. The Shared Socioeconomic Pathways and their energy, land use, and greenhouse gas emissions implications: An overview. Glob Environ Chang 2017;42:153-68. https://doi.org/10.1016/j.gloenvcha.2016.05.009.

[48] Clarke L, Jiang K, Akimoto K, Babiker M, Blanford G, Fisher-Vanden K, et al. Assessing Transformation Pathways. In: Climate Change 2014: Mitigation of Climate Change. Contribution of Working Group III to the Fifth Assessment Report of the Intergovernmental Panel on Climate Change. Cambridge Univ. Press. Cambridge, United Kingdom New York, NY, USA., 2014, p. 413-510.

[49] Rogelj J, Popp A, Calvin K V., Luderer G, Emmerling J, Gernaat D, et al. Scenarios towards limiting global mean temperature increase below $1.5^{\circ} \mathrm{c}$. Nat Clim Chang 2018;8:325-32. https://doi.org/10.1038/s41558-018-0091-3.

[50] Fricko O, Havlik P, Rogelj J, Klimont Z, Gusti M, Johnson N, et al. The marker quantification of the Shared Socioeconomic Pathway 2: A middle-of-the-road scenario for the 21st century. Glob Environ Chang 2017;42:251-67. https://doi.org/10.1016/j.gloenvcha.2016.06.004.

[51] Sacchi R. premise_gwp 2022. https://github.com/romainsacchi/premise_gwp (accessed January 27, 2022).

[52] Terlouw T, Treyer K, Bauer C, Mazzotti M. Life Cycle Assessment of Direct Air Carbon Capture and Storage with Low-Carbon Energy Sources. Environ Sci Technol 2021;55:11397-411. https://doi.org/10.1021/acs.est.1c03263.

[53] Sacchi R, Besseau R, Pérez-López P, Blanc I. Exploring technologically, temporally and geographically-sensitive life cycle inventories for wind turbines: A parameterized model for Denmark. Renew Energy 2019;132:1238-50. https://doi.org/10.1016/j.renene.2018.09.020.

[54] Besseau R, Sacchi R, Blanc I, Pérez-López P. Past, present and future environmental footprint of the Danish wind turbine fleet with LCA_WIND_DK, an online interactive platform. Renew Sustain Energy Rev 2019;108:274-88. https://doi.org/10.1016/j.rser.2019.03.030.

[55] Tannous S, Besseau R, Prieur-Vernat A, Clavreul J, Payeur M, Blanc I, et al. A parameterized model for the estimation of life cycle environmental impacts of crystalline PV systems. 2019. 


\section{PRospective EnvironMental Impact asSEment (premise): a streamlined approach to producing databases for prospective Life Cycle Assessment using Integrated Assessment Models}

Sacchi, R. ${ }^{1, *}$, Terlouw, T. ${ }^{1,2}$, Siala, K. ${ }^{3}$, Dirnaichner, A. ${ }^{3}$, Bauer, C. ${ }^{1}$, Cox, B. ${ }^{4}$, Mutel, C. ${ }^{1}$, Daioglou, V. ${ }^{5,6}$, Luderer, G. ${ }^{3,7}$

1 = Technology Assessment group, Laboratory for Energy Systems Analysis, Paul Scherrer Institut, Villigen, Switzerland

2 = Institute of Energy and Process Engineering, ETH Zurich, Zurich, Switzerland

3 = Potsdam Institute for Climate Impact Research, Potsdam, Germany

$4=$ INFRAS, Bern, Switzerland

5 = Copernicus Institute of Sustainable Development, Universiteit Utrecht, The Netherlands

$6=$ PBL Netherlands Environmental Assessment Agency, The Hague, The Netherlands

7 = Technische Universität Berlin, Berlin, Germany

*Corresponding author: email - romain.sacchi@psi.ch, telephone - +417676219 22, fax - +41 563102199

\section{Supplementary Information}

Contents
A. Battery case study. 2
B. Table - comparison IMAGE vs. REMIND. 4 


\section{A. Battery case study}

Figure A.1 illustrates the climate change impacts for the production of a $1 \mathrm{~kg}$ lithium nickel manganese cobalt oxide (NMC) battery cell. Four assessment years are considered - 2020, 2030, 2040 and 2050 - as well as three IAM scenarios are included from the REMIND model: RCP 6.0, RCP 2.6 and RCP 1.9. The four subplots present different integrations of specific sectors as explained in the main manuscript. In addition, the bar plots display a contribution analysis, to show the climate change impact for NMC battery cells components, such as the anode, cathode and the electrolyte.

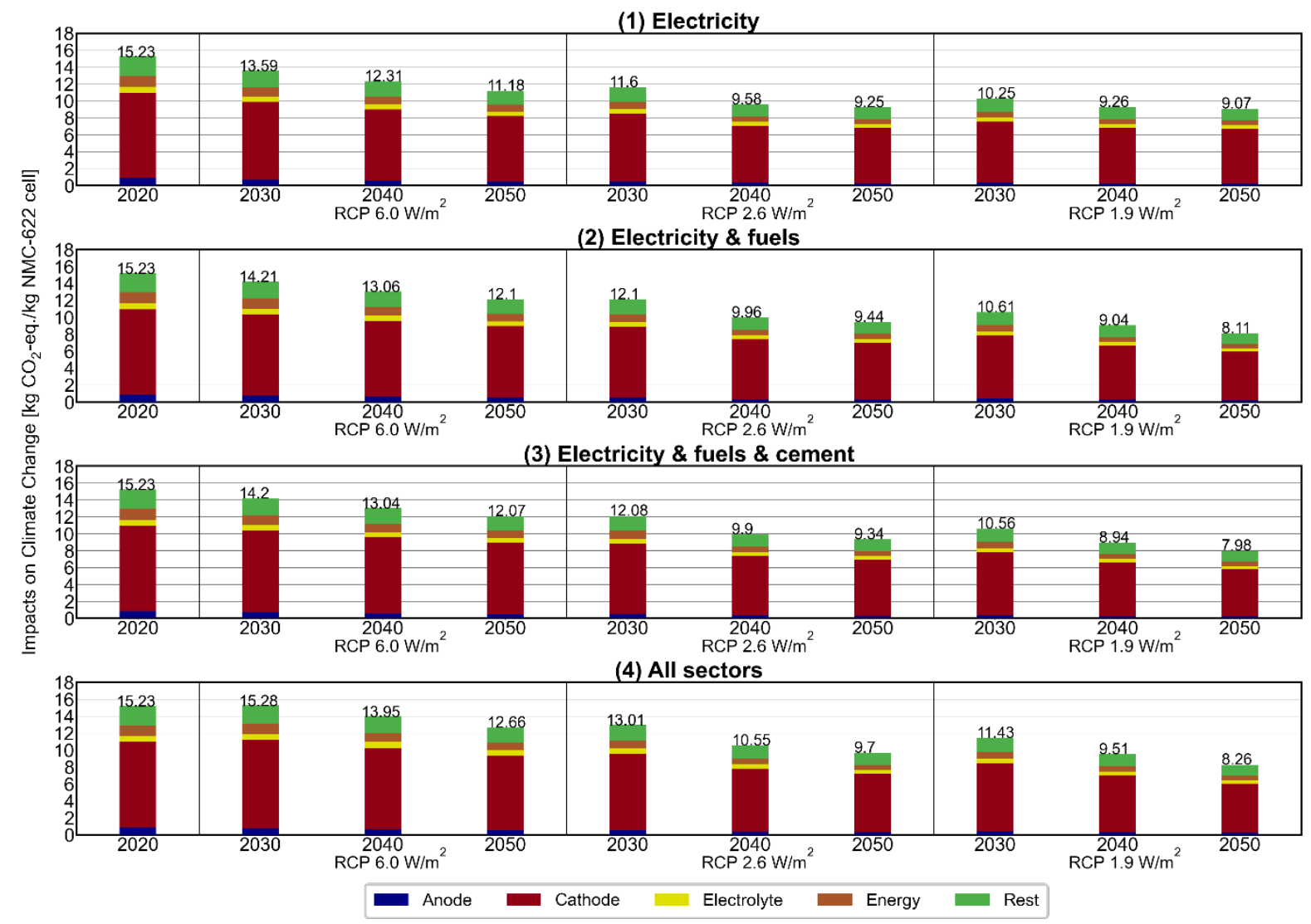

Figure A.1 GHG emission for the production of $1 \mathrm{~kg}$ NMC battery cell, considering different years and climate change mitigation targets

The results demonstrate the biggest influence for the integration of the electricity sector. The reference (static) climate change impact for the production of $1 \mathrm{~kg} \mathrm{NMC} \mathrm{battery} \mathrm{cell} \mathrm{is} 15.2 \mathrm{~kg} \mathrm{CO}$-eq. in 2020 . The prospective integration of the electricity sector results in a decreasing impact on climate change, mainly due to lower GHG emissions generated from energy requirements, because the electricity sector is increasingly dominated by renewable electricity generators. Further, the climate change impact is significantly different between prospective IAM scenarios. The update of the electricity sector in combination with the application of an 
Re-submitted to Renewable and Sustainable Energy Reviews on February ${ }^{1 \text { st }}, 2022$.

optimistic climate scenario - for example RCP 1.9 in 2050 - exhibits $9.1 \mathrm{~kg} \mathrm{CO}$-eq. per kg NMC battery cell, i.e. a GHG reduction of $\sim 19 \%$ compared to the RCP 6 scenario the same year. The influence of the integration of all other sectors in prospective databases is not as strong for NMC battery cell production. The integration of all sectors - for the same IAM scenario RCP 1.9 in 2050 - generates $8.3 \mathrm{~kg} \mathrm{CO}$-eq. per $\mathrm{kg} \mathrm{NMC} \mathrm{battery} \mathrm{cell,}$ i.e. a GHG reduction of $\sim 9 \%$ compared to applying transformations on the electricity sector alone. On the contrary, the integration of all sectors - applying the more conservative RCP 6 scenario - exhibits a slight increase in GHG emissions compared to applying only the transformations on the electricity sector (i.e., 12.66 $\mathrm{kg} \mathrm{CO}$-eq./kWh against 11.18); however, it still represents a GHG decrease of $\sim 17 \%$ in 2050 compared to 2020 (i.e., $12.66 \mathrm{~kg} \mathrm{CO}$-eq./kWh against 15.23).

The improvement of the foreground system of the NMC battery cell is not considered in this assessment, and therefore it can be expected that the (future) environmental impacts of NMC battery cell production could be further reduced due to increased recycling rates and improved energy density of batteries.

\section{B. Table - comparison IMAGE vs. REMIND}

Table B.1 Comparison of midpoint LCIA indicators for $1 \mathrm{kWh}$ from the global low voltage electricity market for 2020, 2030, 2040 and 2050, normalized by the results for 2020 (index 100), following the SSP2-RCP 1.9 prospective scenario.

\begin{tabular}{|c|c|c|c|c|c|c|c|c|}
\hline Change relative to 2020 (Index 100) & \multicolumn{3}{|c|}{ IMAGE } & \multicolumn{3}{c|}{ REMIND } \\
\hline RCP 1.9 W/m & 2020 & $\mathbf{2 0 3 0}$ & $\mathbf{2 0 4 0}$ & $\mathbf{2 0 5 0}$ & $\mathbf{2 0 2 0}$ & $\mathbf{2 0 3 0}$ & $\mathbf{2 0 4 0}$ & $\mathbf{2 0 5 0}$ \\
\hline Ozone Depletion & & & & & & & & \\
\hline Terrestrial Acidification & 100 & 135 & 173 & 190 & 100 & 37 & 16 & 11 \\
\hline Photochemical Oxidant Formation & 100 & 36 & 34 & 35 & 100 & 20 & 9 & 7 \\
\hline Metal Depletion & & & 17 & 18 & 100 & 16 & 9 & 8 \\
\hline Freshwater Ecotoxicity & 100 & 94 & 98 & 102 & 100 & 92 & 91 & 91 \\
\hline
\end{tabular}


Re-submitted to Renewable and Sustainable Energy Reviews on February 1 ${ }^{\text {st }}, 2022$.

\begin{tabular}{|c|c|c|c|c|c|c|c|c|}
\hline Human Toxicity & 100 & 44 & 27 & 28 & 100 & 28 & 19 & 19 \\
\hline Particulate Matter Formation & 100 & 26 & 12 & 12 & 100 & 14 & 6 & 5 \\
\hline Freshwater Eutrophication & 100 & 35 & 11 & 11 & 100 & 14 & 5 & 5 \\
\hline Marine Eutrophication & 100 & 38 & 26 & 26 & 100 & 20 & 10 & 8 \\
\hline Terrestrial Ecotoxicity & 100 & 78 & 92 & 98 & 100 & 177 & 141 & 117 \\
\hline Fossil Depletion & 100 & 58 & 54 & 60 & 100 & 31 & 10 & 5 \\
\hline Ionising Radiation & 100 & 177 & 180 & 150 & 100 & 50 & 39 & 29 \\
\hline Marine Ecotoxicity & 100 & 94 & 98 & 102 & 100 & 91 & 90 & 91 \\
\hline Land Occupation & 100 & 120 & 124 & 137 & 100 & 111 & 133 & 132 \\
\hline Climate Change & 100 & 23 & -1 & -6 & 100 & 22 & 5 & 2 \\
\hline
\end{tabular}

